\title{
Evaluating the greenhouse gas impact from biomass gasification systems in industrial clusters - methodology and examples
}

\author{
Kristina M. Holmgren ${ }^{1,2,{ }^{*}, \text { Thore Berntsson }}{ }^{1}$, Eva Andersson ${ }^{3}$, Tomas Rydberg ${ }^{2}$ \\ ${ }^{1}$ Chalmers University of Technology, Inst of Energy and Environment dep. of Heat and Power Technology, \\ Gothenburg, Sweden \\ ${ }^{2}$ IVL Swedish Environmental Research Institute Ltd, Gothenburg, Sweden \\ ${ }^{3}$ CIT Industriell Energi, Gothenburg, Sweden \\ * Corresponding author. Tel: +46 3177285 37, E-mail: kristina.holmgren@chalmers.se
}

\begin{abstract}
Biomass gasification is identified as one of the key technologies for producing biofuels for the transport sector and can also produce many other types of products. Biomass gasification systems are large-scale industrial systems and it is important to evaluate such systems from economic, environmental and synergetic perspectives before implementation. The objective of this study is to define a methodology for evaluating the greenhouse gas (GHG) impact of different biomass gasification systems and to exemplify the methodology. The ultimate purpose of the methodology is to evaluate the GHG performance of different biomass gasification systems integrated in industrial clusters. A life cycle perspective is applied.

Most biomass gasification systems are multiproduct systems, simultaneously producing biofuels, heat at different temperatures and pressures and electricity. The value, in economic terms and in terms of GHG emissions, is well defined for some products (e.g. biofuels), whereas for other products (such as heat and electricity) it is more uncertain and in some cases dependent on time and location.
\end{abstract}

Keywords: Greenhouse gas impact assessment, Biomass gasification, System analysis

\section{List of abbreviations}

DH district heating

FT Fischer-Tropsch

GHG greenhouse gas

GWP Global Warming Potential
MTO methanol to olefins

$P E$ polyethylene

$P P$ polypropylene

SNG Synthetic natural gas

\section{Introduction/background}

Biomass gasification is seen as an important technology for the future production of biofuels. This paper is part of the project "Advantages of regional industrial cluster formations for the integration of biomass gasification systems" which aims to evaluate the economic performance and greenhouse gas (GHG) impact of different biomass gasification systems. The study is performed as a cas e study in south-west Sweden, focusing on the technical systems and opportunities for integration with existing industries and infrastructure. This paper discusses the methodology for evaluating the GHG performance of the different gasification systems from a life cycle perspective.

Life cycle assessments of bioenergy systems available in literature were analysed by [1] concluding that the use of different input data, functional units, allocation methods, reference systems etc. contributes to a wide range of results for similar systems and complicates the comparison between studies. Wetterlund et al. [2] show the effects of applying system expansion in the well-to-wheel $\mathrm{CO}_{2}$ evaluation of biofuels. Our approach is similar to the one taken by [2], but we apply it to systems with a wider range of products and include non- $\mathrm{CO}_{2}$ GHG emissions from all parts of the chain, and soil emissions from biomass production. We also describe how products with a longer lifetime can be handled in the evaluation. 


\section{Objective}

This paper outlines and exemplifies a methodology for evaluating the GHG impact of biomass gasification systems integrated with other industries and infrastructure. The methodology is suitable for comparing alternative configurations and could also be applied to other bioenergy systems. The outlined methodology has a 1 ife cycle perspective, addressing the potential climate impact in terms of GWP (global warming potential)-summarised emissions. The methodology does not predict absolute environmental impacts.

\section{The scope of the evaluation}

Depending on scope, a GHG evaluation could answer different questions. The methodology of this paper includes two different aspects:

i) How much do the biomass-based systems reduce emissions compared to the conventional (often fossil-based) systems?

ii) In which applications does the biomass-utilisation result in the largest emission reductions?

We take a co nsequential approach and marginal data should therefore be used [3] for the assessment, since possible changes in the production could affect the directly or indirectly related marginal suppliers and competing products. Further, we include global emissions of carbon dioxide, methane and nitrous oxide, using GWP factors 1, 25, and 298 respectively based on [4]. Fig. 1 shows the two systems to be compared in order to answer the first question above. Comparing several biomass-based systems to their reference (as in Fig. 1) can help answering the second question.
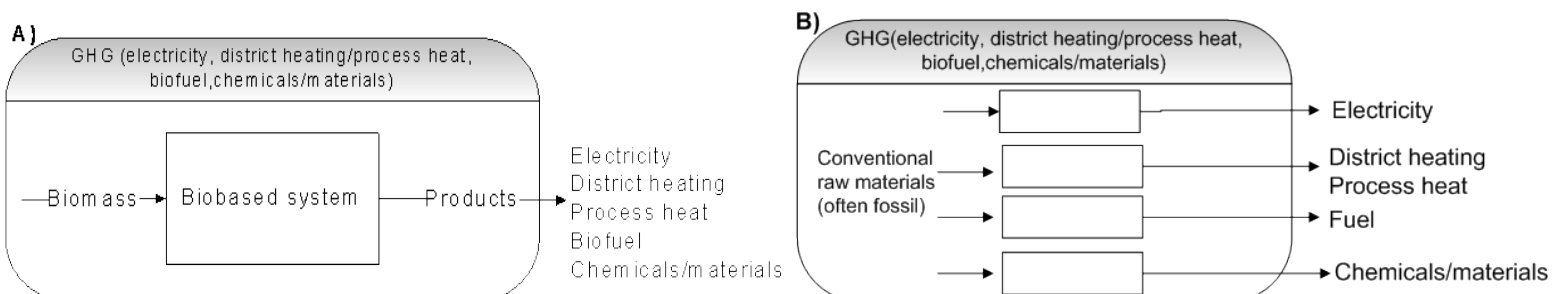

Fig. 1. Comparison between reference system (B) and biomass based system (A). The same amount of each product is produced in each system.

\section{Methodological aspects}

In this section we describe how important factors in the GHG evaluation process of the biomass gasification system should be treated, including; system boundaries, reference system and life cycle data from other studies. In the next section we exemplify our methodology.

\subsection{System boundaries}

Fig. 2 is a schematic view of the conceptual system and system boundaries of the biomass gasification system integrated with industry evaluated in this study. The geographical boundaries for the different parts of the system and the chosen time perspective should be taken into consideration [5]. The geographical boundaries could limit raw material supply, infrastructure for the transport and delivery of products and could also define the framework for the choices of reference systems. The time perspective can help to define the appropriate reference systems by giving a context for technology development. Even though focus is on the conversion system it is important to include both downstream and upstream systems. 


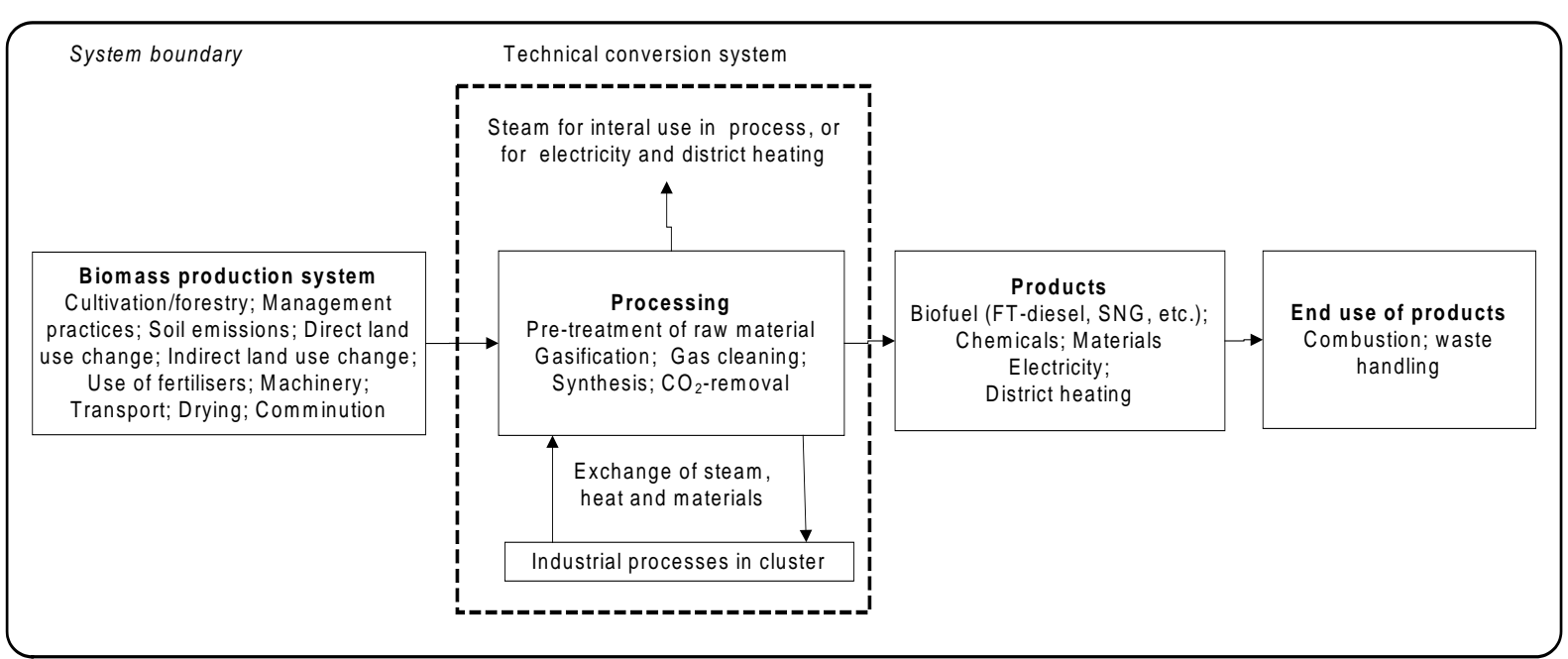

Fig. 2. Schematic view of conceptual system and system boundaries of the biomass gasification system evaluated in this study.

\subsection{Functional unit}

The functional unit is $\mathrm{g} \mathrm{CO}_{2 \text { eq. }} \mathrm{MJ}^{-1}$ biomass input. This unit was chosen since the evaluation focuses on the technical conversion system and the amount of input biomass is the same in all systems. For further discussion on the choice of functional unit, see [1,2].

\subsection{Reference system}

The reference system, Fig. 1B, is the conventional system to which the proposed biomassbased system, Fig. 1A, is compared. In the case of the biomass gasification system (and other multiproduct systems) the reference is not one single system but rather separate systems for each product. In most cases the reference is fossil fuel-based, but not necessarily. For future systems, such as in this study where different configurations of new installations are investigated, the definition of the reference system requires significant analysis.

\subsubsection{Electricity}

The reference for electricity should be the future marginal production technology determined by build margin [2]. Energy market scenarios with consistent assumptions for future prices and technologies could be used for determining the likely marginal production technology. Axelsson et al, [6], have developed a tool (ENPAC) for generating consistent energy market scenarios. The inputs to the tool are fossil fuel prices, levels of policy instruments $\left(\mathrm{CO}_{2}-\right.$ charge, green electricity certificates) and available technologies and technology developments for electricity production. The output is scenarios that include future fuel prices, energy carrier prices and associated $\mathrm{CO}_{2}$ emissions. The electricity price includes the cost for building new capacity and hence the marginal electricity production from the tool is the future build margin. This tool can be used in order to determine the appropriate marginal technologies for electricity production.

\subsubsection{Heat}

Prices from the ENPAC tool together with knowledge of local conditions for DH can be used to determine the appropriate reference for heat delivery. Infrastructure and possibilities for expansion are crucial for the performance (environmental and economic) of a bioenergy system with potentially large DH delivery [7]. Excess heat from a new biomass gasification unit running 8000 hour s per year will constitute a base load to the $\mathrm{DH}$ system and the corresponding production technology for this load should be used as reference. The excess 
heat from a gasification unit can even result in significant reductions in emissions when it replaces biomass-based $\mathrm{DH}$, since the excess heat will save biomass that can be used elsewhere. Excess heat can also be delivered to an adjacent industry, whereby emission reductions then correspond to fuel or other resource savings.

\subsubsection{Biomass}

GHG emissions from the biomass production system could constitute a significant part of the overall emissions from the bioenergy system $[8,9]$ and should take all sources into account, including soil carbon losses due to management and land use change. Biomass gasification generally requires significant pre-treatment of the biomass and all these treatments should be included irrespective of where they are performed. Since the amount of biomass available for energy purposes is, and will continue to be, limited it is important to include an alternative use of the biomass in the reference system [10,2]. In a European perspective the marginal biomass user is identified as coal power plants with co-combustion possibilities or possibly (if strong policy instruments are applied) biofuel producers [6]. Other marginal users, such as biomass combined heat and power plants could also be feasible under certain circumstances.

\subsubsection{Biofuels}

The reference for biofuels could be conventional fuels: diesel, petrol or a combination of the two. These are appropriate references even for future scenarios with a time frame of 10-20 years, since it is likely that these fuels will constitute a significant part of the use even in the coming decades. In Table 2 the chosen reference for biofuels used in this study is presented.

\subsubsection{Materials and chemicals}

Biosyngas can also be used for the production of chemicals and materials. The reference for these products should be similar products produced by the conventional route. The end use could be complex since there might be several uses of the product although it will be similar to the conventional product. In our approach we take into consideration the incineration at the end of life and that some products act as carbon storages due to long lifetime by applying the method outlined in $[11,12]$. The latter point means that we apply a factor that reduces the GWP-value. The reduction of the GWP-value will be larger the longer the lifetime of the product. In the calculations we have used the simplified approach as suggested by [11].

\subsection{Life cycle data from other studies}

Our focus is on the technical conversion system (biomass gasification) and emission and energy consumption data for the other parts of the system and reference flows are taken from literature. However, these life cycle data need to be recalculated to ensure that assumptions are consistent for co-product allocation, marginal production of electricity etc.

\section{Examples}

In order to exemplify our methodology we show GHG emission reduction potential for three different types of biomass conversion systems; one biomass gasification unit producing FTproducts [13], one biomass gasification unit producing bio-SNG (synthetic natural gas) [14] and one biomass gasification unit producing methanol [7] with a down-stream MTO-process (methanol to olefin) producing PE (polyethylene) and PP (polypropylene) [15]. The input and output to the installations are given in Table 1 and the GHG emission reductions for different cases of assumptions for reference streams are shown in Fig. 3.The different cases are explained in Table 2. The plants have been scaled so as to have the same biomass input. In all cases, the input is wet (50\% wt.) forest residues that are dried using excess heat from the 
conversion process. Emission factors for the different fuels and materials are taken from literature [16-23]. The assumed annual operation time is 8000 hours for all plants.

Table 1. Capacity data for example installations.

\begin{tabular}{lcccccc}
\hline Conversion & \multicolumn{2}{c}{ Input (MW) } & Output (MW) & & \\
Plant & Biomass & Electricity & FT-products & SNG & PE/PP (kton yr $\left.{ }^{-1}\right)$ & Heat $^{\mathrm{a}}$ \\
\hline FT & 371 & 9.8 & 167 & & & 50 \\
SNG & 371 & -15.3 & & 265 & & 89 \\
MeOH/PE\& PP & 371 & 37 & & & $32.1 / 15.7$ & 134 \\
\hline
\end{tabular}

${ }^{\mathrm{a}}$ In the base case the maximum amount of deliverable $\mathrm{DH}$ is $300 \mathrm{GWh} \mathrm{yr}^{-1}$ for all biorefineries. In the case of heat delivery to industrial process the delivered amount is $711 \mathrm{GWh}$

\section{Results}

The results (Fig. 3) show that there is a significant difference between total impacts depending on assumptions made for the reference streams. Only one reference use of electricity is displayed but it constitutes a significant part of all chains. Also the GHG savings due to DH delivery constitute a significant part of the savings in most cases. Hence, it is important to make calculations for scenarios using different possible references for these flows

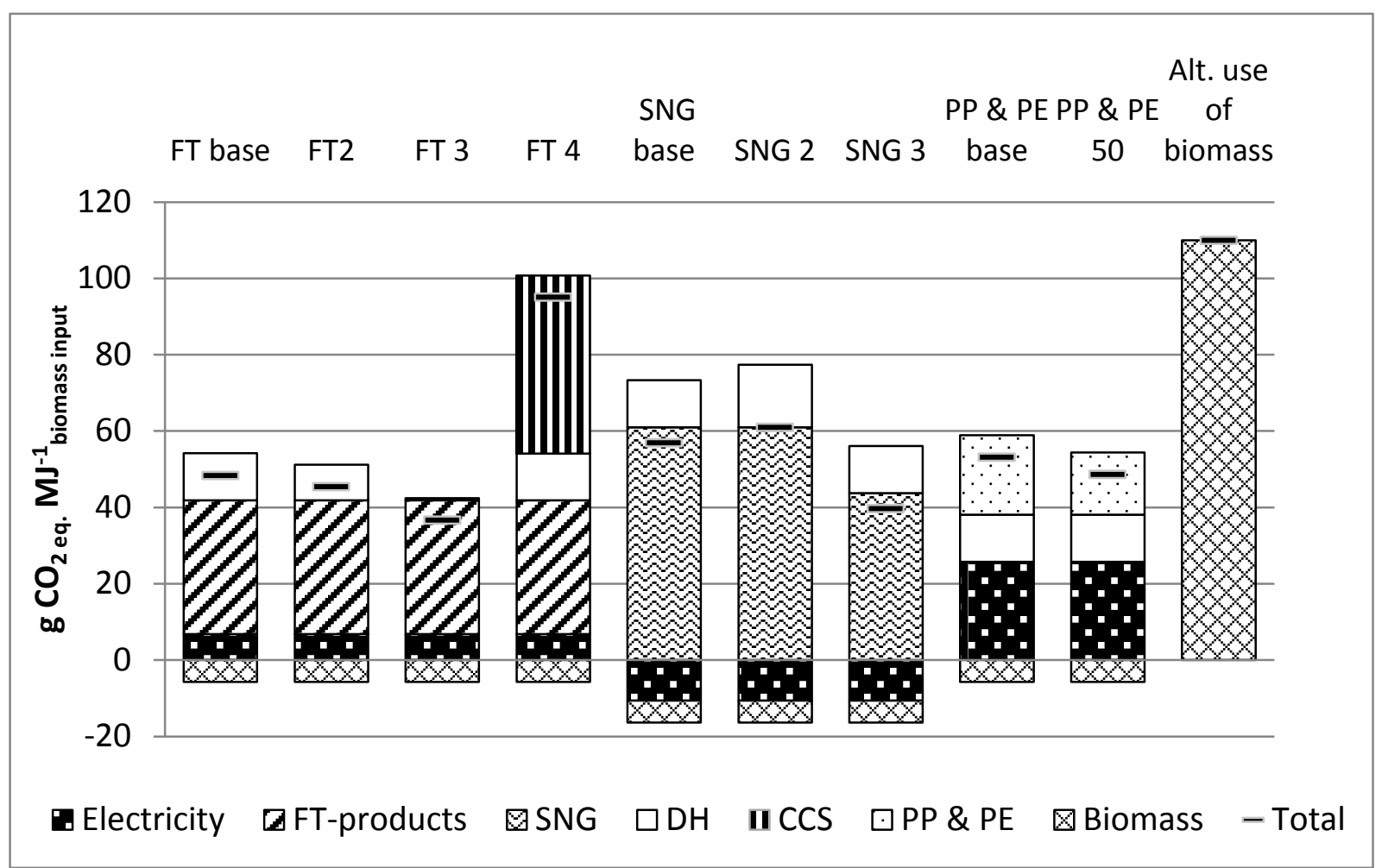

Fig. 3. GHG emissions savings for different reference systems for the different conversion systems. Positive values mean net savings of emissions compared to reference system. Alternative use of biomass is co-combustion in coal power plant.

In FT 3 we show the effect of not taking into consideration that biomass is a limited resource and thereby could save emissions by being used elsewhere. In FT 3 the emissions savings due to the $\mathrm{DH}$ delivery is reduced to the savings of not producing and utilising the biomass. The chosen reference systems of other products are of some importance e.g. case SNG 3, where the bio-SNG replaces natural gas in industry instead of petrol in cars. Case FT 4 shows that $\mathrm{CCS}$ at the biomass conversion plants is of significant importance. Our results also show that 
the conversion to plastics results in significant savings compared to the fossil route. The significant electricity production in the methanol plant is an important part of the savings in these cases and in addition the electricity production possible from the end use of the materials (incineration) is also an important part of the total savings from the material part. The delay of emissions due to the lifetime of products had little impact, mainly since the delay will also occur in the reference system and the crediting for the electricity produced at incineration is delayed. Further, all of the gasification systems showed lower potential for GHG reduction than using the biomass for co-combustion in a coal power plant. This means that even though the biomass gasification systems result in net savings compared to the fossil systems, they are not optimal solutions for GHG mitigation when biomass is a limited resource.

Table 2. Assumptions for the different cases presented in Fig. 3.

\begin{tabular}{|c|c|}
\hline Case & Assumptions \\
\hline $\begin{array}{c}\text { FT, } \\
\text { SNG and } \\
\text { PE \& PP } \\
\text { base }\end{array}$ & $\begin{array}{l}\text { Reference electricity is produced in coal power plant. SNG replaces petrol in } \\
\text { private cars. } 85 \% \text { of FT-products replace diesel in heavy duty vehicles and } 15 \% \\
\text { replace petrol in private cars (based on [13]). Bio-based PE and PP replace } \\
\text { fossil PE and PP based on naphtha, the end use is assumed to be short lived } \\
\text { products ( }<1 \text { yr.). DH replaces biomass boiler; } 300 \mathrm{GWh} \text { heat can be delivered } \\
\text { from each of the plants. The delivery of DH leads to a reduction in biomass } \\
\text { demand corresponding to the amount needed in the biomass boiler, which } \\
\text { instead can be used in coal power plant. }\end{array}$ \\
\hline FT 2, SNG & $\begin{array}{l}\text { DH replacing natural gas boiler in industry. Greater amount of DH can be } \\
\text { delivered due to higher number of operational hours in industry. }\end{array}$ \\
\hline SNG 3 & SNG replaces natural gas in industry \\
\hline FT 3 & $\begin{array}{l}\text { d limited. The reduction in biomass utilisation } \\
\text { lead to increased use in coal power plant. }\end{array}$ \\
\hline FT 4 & CCS is applied. $50 \%$ of coal in biomass could be stored away (based on [24]) $)^{\mathrm{a}}$ \\
\hline $\begin{array}{l}\text { PE \& PP } \\
50\end{array}$ & $\begin{array}{l}\text { The lifetime of the end products is assumed to be } 50 \text { years, and the carbon } \\
\text { storage in products is taken into account according to method by }[11,12]\end{array}$ \\
\hline $\begin{array}{l}\text { Alt. use of } \\
\text { biomass }\end{array}$ & $\begin{array}{l}\text { Alternative use of biomass. Includes emissions from the life cycle of biomass } \\
\text { and reductions from the saving of coal utilisation in co-combusted power plant. }\end{array}$ \\
\hline
\end{tabular}

\section{Discussion}

Few studies include a reference use of the biomass $[2,26]$ but our examples show that the biomass reference impacts results significantly. It is important to include either a reference use of the biomass or a reference land use [1]. Even though our results show that using biomass for co-combustion in coal power plants has higher potential of reducing GHG emissions, there are several reasons to further investigate the gasification systems. Transportation biofuels constitute an alternative to the limited fossil sources, and are thereby not only a solution to GHG mitigation. Further, conversion and efficiency data for our examples were taken from literature. However, the availability of data on opt imized and integrated processes is limited and needs further investigation. For example, SNG processes with reduced or no electricity demand do exist at smaller scale and FT-processes have good possibilities for carbon capture. According to our results, such systems show GHG emission reductions comparable to the savings in a co-combustion plant. Knowledge of the methanol production plant with the downstream MTO process is very limited and needs to be investigated further. Our results show that reference electricity and DH production are important parameters for sensitivity analysis. A scenario approach using the tool from [6] 
could be used for this. The LCAs of other reference products should also be adapted to the assumptions of the scenarios.

A LCA for a biorefinery concept, producing chemicals, based on switchgrass showed that the biomass production chain had a significant impact on the overall result [27]. However, in our case, using forest residues, both land use emissions and fertilisers are of little importance and hence the biomass production chain constitutes only a small part of total emissions. Since gasification units might use different biomass feedstock it is important to state which biomass has been used for a specific GHG evaluation.

\section{Future work}

Biomass gasification systems should be studied in more detail. Increased integration and optimal solutions could possibly increase emissions savings to levels comparable to those of using the biomass for coal co-combustion in power plants.

\section{Acknowledgments}

The research has been supported by Göteborg Energi, E.ON Gasification Development AB, Preem AB, Perstorp Oxo AB, Formas, the Swedish Environmental Protection Agency and the Swedish Energy Agency, which are gratefully acknowledged.

\section{References}

[1] Cherubini, F., Strømman, A.H. 2011. Life cycle assessment of bioenergy systems: State of the art and future challenges. Bioresource Technology, vol. 102, pp 437-451.

[2] Wetterlund, E., Pettersson, K. \& Magnusson M. 2010. Implications of system expansion for the assessment of well to wheel $\mathrm{CO}_{2}$ emissions from biomass-based transportation. International Journal of Energy Research, vol. 34 pp. 1136-1154.

[3] ISO 14044:2006 Environmental management - Life cycle assessment - Requirements and guidelines.

[4] IPCC (2007) Climate change 2007: The physical science basis. Contribution of working group 1 to the fourth assessment report of the International Panel on Climate Change. Cambridge University Press, Cambridge, UK

[5] ISO 14040:2006 Environmental management - Life cycle assessment - Principles and Framework.

[6] Axelsson, E., Harvey, S., Berntsson T. 2009. A tool for creating energy market scenarios for evaluation of investments in energy intensive industry. Energy, 34, pp. 2069-2074.

[7] Ericson K. \& Börjesson, P. 2008. P otential utilization of biomass in production of electricity, heat and transportation fuels including energy combines -Regional analyses and examples. Lund University. Report no 64. (In Swedish; English summary).

[8] Zah, R., Böni, H., Gauch, M., Hischier, R., Lehmann, M., Wäger, P. 2007. Life Cycle Assessment of energy products. Environmental assessment of biofuels. Executive summary. EMPA - Technology and Society Lab. Switzerland.

[9] UNEP 2009. Towards sustainable production and use of resources: Assessing biofuels.

[10]Cherubini, F., Bird, N.D., Cowie, A., Jungmeier, G., Schlamadinger, B., Woess-Gallasch, S. 2009. Energy and greenhouse gas based LCA of biofuels and bioenergy systems: Key issues, ranges \& recommendations. Resources, Conservation and Recycling, 53, 434-447. 
[11]Clift, R. \& Brandao, M 2008. C arbon storage and timing of emissions. Briefing Note dated $20^{\text {th }}$ October 2008. Centre for Environmental Strategy, University of Surrey.

[12]PAS 2050:2008. Specification for the assessment of the life cycle greenhouse gas emissions of goods and services. BSI October 2008. ISBN 9780580509780.

[13] Axelsson E., Overland, C., Nilsson, K. \& Sandoff, A. 2008. B ioenergikombinat i fjärrvärmesystem. Svensk Fjärrvärme Rapport 2009:11. (In Swedish).

[14]Börjesson, M., \& Ahlgren E.O. 2010. Biomass gasification in cost-optimized district heating systems - A regional modeling analysis. Energy Policy vol. 38 pp. 168-180.

[15]Nouri, S., Kaggerud, K. 2006. W aste-to-plastics: process alternatives. Chalmers University of Technology, Gothenburg, Sweden. CPM-report 2006:10.

[16]Edwards, R., Larivé, J-F. Mahieu, V. \& Rouveirolles, P. 2007. Well-to-wheel analysis of future automotive fuels and powertrains in the European context. Well-to-wheels Report. Version 2c, March 2007. Available at http://ies.jrc.ec.europa.eu/WTW

[17]Uppenberg, S., Almemark, M., Brandel., M., Lindfors, L.-G.; Marcus, H.-O., Stripple, H., Wachtmeister, A. Zetterberg, L. 2001. Miljöfaktabok för bränslen. Bakgrundsinformation och Teknisk bilaga. IVL report B1334B-2, Stockholm, Sweden. (In Swedish).

[18]Gode, J., Martinsson F., Hagberg, L., Öman, A. \& Höglund, J. Miljöfaktaboken 2010 Emission factors for fuels, electricity, heat and transport in Sweden. Värmeforsk; Sweden. (In prep.)

[19]Lindholm, E.-L., Berg, S., Hansson, P.A. 2010. Energy efficiency and the environmental impact of harvesting stumps and logging residues. Eur J For Res vol. 129, pp. 1223-1235.

[20]Liptow C., Tillman, A.-M., 2009. Comparative life cycle assessment of polyethylene based on sugar cane and crude oil. Chalmers University of technology, Dep. of Energy and Environment, div. of Environmental Systems Analysis. Report no 2009:14

[21]Kirkinen, J., Palosuo, T., Holmgren, K., \& Savolainen, I. 2008. Greenhouse impact due to the use of combustible fuels: life cycle viewpoint and relative radiative forcing commitment. Environmental Management vol. 42, pp. 458-469.

[22]Lindholm, E.-L., 2010. Energy use and environmental impact of roundwood and forest fuel production in Sweden. Doctoral Thesis. Swedish University of Agricultural Sciences.

[23]Harding, K.G., Dennis, J.S., von B lottnitz, H. \& Harrison, S.T.L. 2007. Environmental analysis of plastic production processes: Comparing petroleum-based polypropylene and polyethylene with biologically-based poly- $\beta$-hydroxybutric acid using life cycle analysis. Journal of Biotechnology vol. 130, pp. 57-66.

[24]Larson, E. D., Jin, H., \& Celik, F.E. 2005. Gasification-based fuels and electricity from Biomass, with and without carbon capture and storage. Princeton Environmental Institute, Princeton University, Princeton, NJ, October 2005, 77 pp.

[25]Holmgren, K., Hagberg, L. 2009. Life cycle assessment of climate impact of FischerTropsch diesel based on peat and biomass. IVL report B1833.

[26] Andersson, E., Harvey, S. 2007. Comparison of pulp-mill-integrated hydrogen production from gasified black liquor with stand-alone production from gasified biomass. Energy, 32 (4) pp. 399-405.

[27]Cherubini, F., Jungmeier, G. 2010. LCA of a biorefinery concept producing bioethanol, bioenergy and chemicals from switchgrass. Int J Life Cycle Assess, vol. 15, pp. 53-66. 